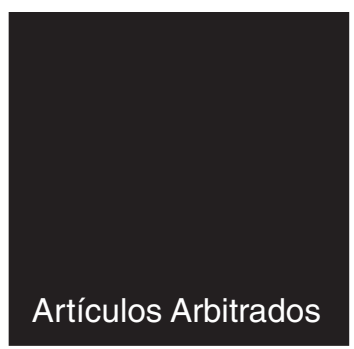

\title{
Ciudad compacta vs. ciudad difusa Ecos antiguos y recientes para las políticas de planeación territorial y espacial
}

\section{Tadeo Humberto Sanabria Artunduaga}

Arquitecto. Magíster en Gestión y Valoración Urbana. Magíster en Ordenamiento Urbano y Regional. Doctorando del Programa en Gestión y Valoración Urbana y Arquitectónica de la Universidad Politécnica de Cataluña. Grupo de Investigación Prospectiva Urbano-Territorial. Se desempeñó como docente en planeación territorial y lideró la formulación de planes de ordenamiento territorial en varios municipios de Colombia por más de diez años. Actualmente trabaja en el proyecto de investigación Aprovechamientos urbanísticos y modelos de ocupación. Estimación de cargas y beneficios urbanísticos a partir de demandas de servicios urbanos como docente-investigador de la Fundación Universidad de América en Bogotá, Colombia.

Tadeo.sanabria@investigadores.uamerica.edu.co.

\section{John Fredy Ramírez Ríos}

Sociólogo. Magíster en Urbanismo de la Universidad Nacional de Colombia. Grupo de Investigación Prospectiva Urbano-Territorial. Se desempeñó como docente en programas de posgrado enfocados en temas de la planeación territorial y de investigación aplicada. Actualmente trabaja en el proyecto de investigación Determinantes del territorio para la competitividad urbana. Propuesta de medición y conceptualización como docente-investigador de la Fundación Universidad de América en Bogotá, Colombia.

john.ramirez@investigadores.uamerica.edu.co.

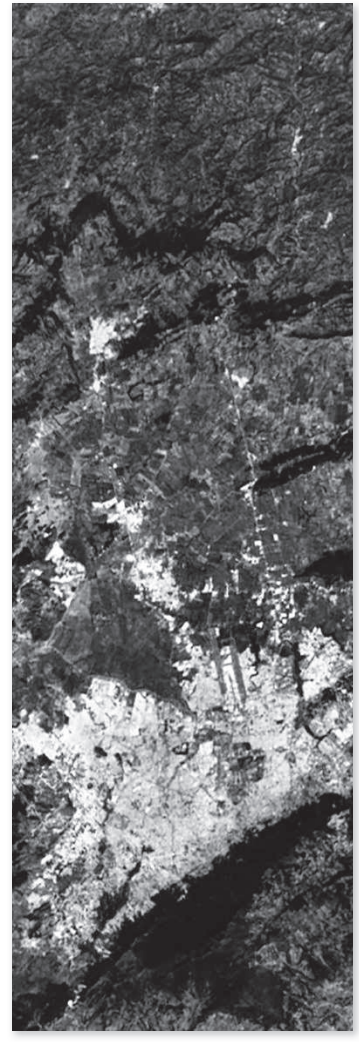




\title{
Resumen
}

En Colombia, las políticas territoriales de naturaleza espacial, tanto a escala nacional como municipal, usualmente indican que las tendencias de crecimiento de las ciudades se deben orientar de tal manera que se preserve en ellas una forma urbana compacta. Este artículo explora las razones ideológicas que dan fundamento a esa idea dominante, con el fin de evaluar las justificaciones empíricas contemporáneas que demuestran las "ventajas” o "desventajas", ya sea tanto de la compacidad como de la difusión urbana. En tiempos recientes es relevante esta reflexión, dada la idea dominante de basar los modelos de crecimiento urbano en la compacidad y cuestionar los alcances teóricos que tienen este tipo de políticas en la planeación territorial y espacial.

\section{Palabras clave}

Ciudad compacta; ciudad difusa; políticas de planeación territorial y espacial; forma urbana.

\begin{abstract}
Compact vs. Sprawl city. Theoretical perspectives in spatial policies.

In Colombia local and national urban and regional policies suggest that urban growth should be guided with the aim of fostering compact urban forms. They are generally opposed to any urban dispersal to avoid sprawl. This paper explores the ideological foundations of the compact city and evaluates contemporary empirical evidence to demonstrate the advantages or disadvantages of such urban form. This debate has become relevant because urban growth Master Plans based on the compact city idea predominate, but many of them do not question the effects of these kinds of policies on contemporary urban and regional planning.
\end{abstract}

\section{Keywords}

Compact city; sprawl; spatial planning policies; urban form. 


\section{Introducción}

Recientemente en Colombia se ha reavivado con intensidad el debate académico y político acerca de la manera más adecuada de orientar las fuertes tendencias de crecimiento urbano expansivo, que no solo las grandes ciudades están experimentando, sino otras que hace muy poco tiempo dejaron la condición de ser pequeños y marginales centros poblados. Son paradigmáticos los casos de Yopal y Tunja, ubicadas al norte de la capital Bogotá, que obligadas por un boom constructivo de tipo residencial y comercial ya han ampliado sus perímetros urbanos.

Las políticas públicas territoriales y espaciales, tanto locales como nacionales, buscan que esas tendencias de crecimiento no rompan con la compacidad de las formas urbanas, que tradicionalmente han caracterizado a las ciudades colombianas y latinoamericanas (DEPARtamento Nacional de Planeación, 2005: 253). Ellas sugieren mantener los atributos urbanos propios de la compacidad, que son los siguientes de acuerdo con la síntesis ofrecida por Yu-HSINTsai (2005: 142): altas densidades (GoRDON, RichaRdson \& WoNG, 1986), mezcla de usos del suelo, vivienda y trabajo (Ewing, 1997), presencia ya sea de mono o poli centralidades urbanas (ANDERSON ET ÁL. 1996). Además, la existencia de un núcleo urbano para la vida comunitaria que le dé sentido de espacio público y político a la ciudad (Fishman, 1998; AudiRAc, SHERMYeny Smith, 1990; Neuman, 1991).

Sin embargo, los proyectos de desarrollo urbano que materializan las políticas territoriales son contradictorios o ambiguos en la práctica frente a esos propósitos de compacidad de la política. Muchos de los proyectos de vivienda promovidos tanto por el sector oficial como por el privado se han ejecutado de manera dispersa en suelos rurales y de expansión, que empiezan a evidenciar los atributos propios de las formas urbanas difusas: desarrollos inmobiliarios horizontales, bajas densidades habitacionales, alta especialización del suelo y despreocupación por la consolidación de centralidades para la vida comunitaria, social y política. Igualmente se están observando formas urbanas mixtas que combinan, por ejemplo, atributos de alta densidad habitacional con alta especialización del suelo.

En el caso de la vivienda ofertada para poblaciones de ingresos bajos (vivienda de interés prioritaria - VIP) e ingresos medio-bajos (vivienda de interés social - VIS), los municipios que lideran su gestión como promotores tanto son presionados por las políticas nacionales que 


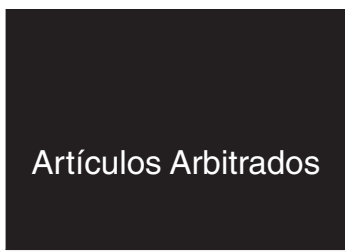

Tadeo Humberto Sanabria Artunduaga y John Fredy Ramirez Ríos

buscan la reducción del déficit cuantitativo habitacional como también por la necesidad de participar de los subsidios de urbanización provistos desde el presupuesto nacional. Estas situaciones los llevan a disponer rápidamente de suelos propiedad del municipio, para facilitar el proceso de ejecución de los proyectos, sin importar la cercanía o lejanía que estos tengan del centro urbano consolidado. El afán es construir las viviendas, sin importar muchas veces dónde, y manteniendo a su vez altas densidades habitacionales, que aseguren el cierre financiero de los proyectos. Es el caso de lo que puede estar ocurriendo en el corredor regional Bogotá-Facatativá descrito en la figura 1.

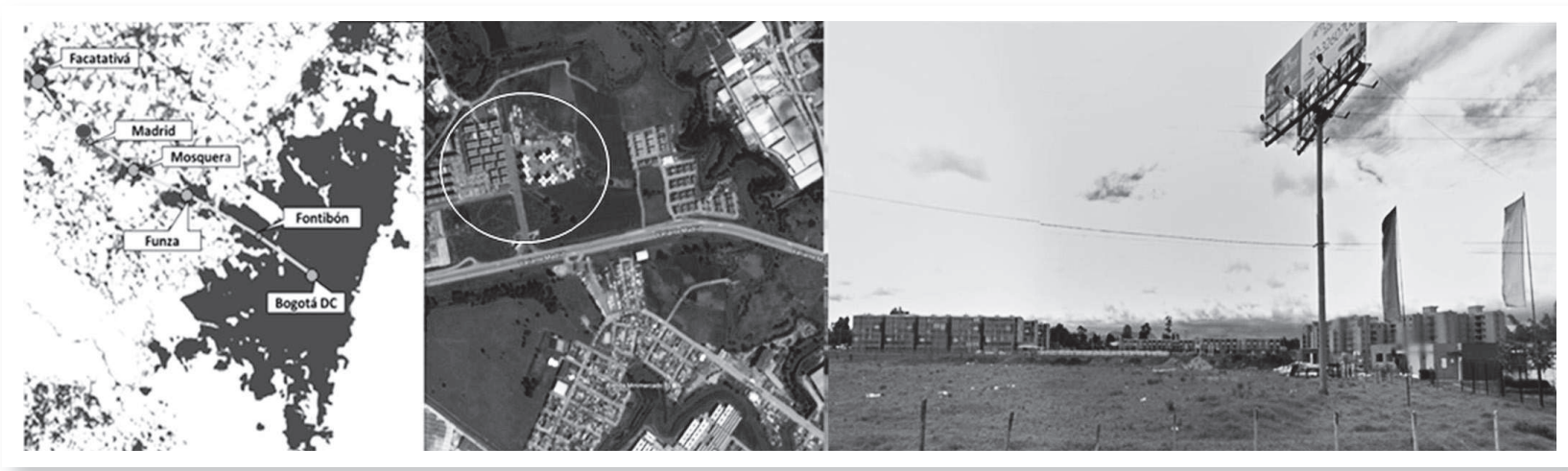

Figura 1. Crecimiento expansivo difuso en densidades altas sobre la conexión Bogotá-Facatativá. Fuente: elaboración propia con base en datos de SALDÍAS, 2009 e imágenes del servidor Google Maps, 2017
En el caso de la vivienda ofertada para altos ingresos, las tendencias de expansión son aún más dramáticas, debido, por un lado, a los privilegios de bienestar y de clase asociados a la baja densidad habitacional, pero también por la inacción de las entidades públicas que, se supone, deben hacer cumplir las directrices de control urbano que eviten que esas tendencias rompan con la compacidad de los municipios. Se suma la complicidad de algunos gobiernos locales que obtienen beneficios personales o clientelares al permitir este tipo de suburbanizaciones o residencias en suelos rurales de sus jurisdicciones territoriales, y cuyos costos fiscales, sociales, de infraestructura y dotacionales trasladan de manera irresponsable a las administraciones siguientes. 
También los proyectos de renovación o redesarrollo urbano que se ejecutaron en suelos centrales no tuvieron el impacto positivo atribuido al fomento de una forma urbana compacta. Ejemplo de lo anterior es el proyecto VIP La Hoja en pleno corazón de Bogotá (figura 2). Formó parte de una política local que buscaba contener una mayor atomización de la capital a lo largo de la Sabana Cundiboyacense, y fortalecer la mezcla e inclusión sociales, por medio de la oferta de este tipo de vivienda en suelos altamente valorizados de la capital. Hasta el momento, los efectos visibles del proyecto desmienten todas las bondades aparentes de promover una ciudad compacta e incluyente, a saber: hacinamiento, guetización intraurbana, deterioro del entorno y agudización de la exclusión social y expulsión de poblaciones de altos ingresos a zonas suburbanas o rurales, entre otros.

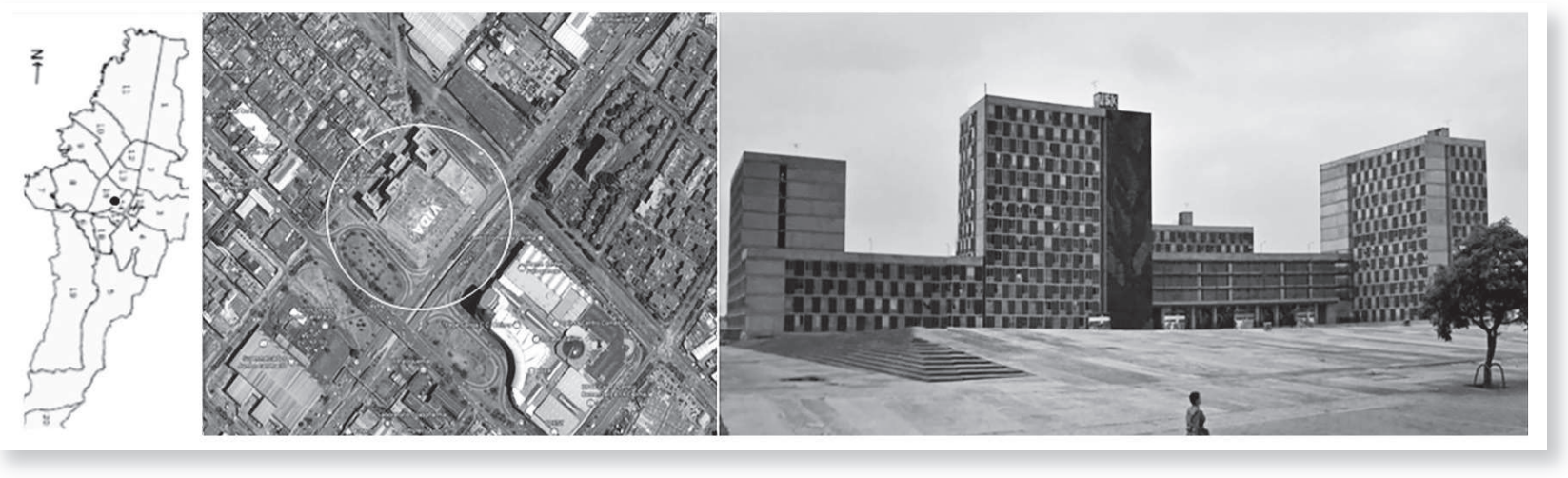

Figura 2. Proyecto de la

A pesar de los resultados contradictorios de la política, es persistente la idea de la compacidad urbana como la más legítima y deseable. Defender sus atributos urbanos es usualmente considerado progresista, eficiente y adecuado. Es, además, coherente con la sostenibilidad del crecimiento urbano y con los discursos académicos que lo abanderan: smartcities, smartgrowth, new urbanism, entre otros. Se asume que la forma urbana compacta facilita Hoja en Bogotá. Contexto de localización y fotografía del conjunto. Fuentes: imágenes tomadas del servidor de Google Maps, 2017 la proximidad de los actores en el territorio, un mayor y mejor acceso a la información, una menor energía invertida en movilidad, la multiplicación de los intercambios y la reducción de medios de transporte mecánicos y contaminantes (RUEDA, 2002). 
Lo curioso es que hasta hace muy poco no existió una metodología cuantitativa específica que estableciera los grados de compacidad o de dispersión de una forma urbana, ni tampoco una batería estándar de indicadores que sirviera para comparar valores ideales asignados a variables de crecimiento urbano que tendieran a la compacidad (Tsal, 2004: 143-144). Ello sugiere que muchos de los argumentos usados en pro de la compacidad, si bien pueden contar con toda la consistencia y validez empírica $-\mathrm{y}$ esta reflexión no discute sobre ello-, comparten unos supuestos ideológicos asociados a visiones divergentes alrededor de lo que es el urbanismo y de la ciudad como su objeto de estudio. Esta reflexión rastrea el origen histórico y la persistencia de esos supuestos, y confronta con las nuevas evidencias que demuestran las potenciales ventajas y desventajas de ambas formas urbanas. Igualmente se analizan las implicaciones que ello tiene para las políticas territoriales y espaciales que tengan como objeto la orientación de tendencias de crecimiento urbano.

\section{Método de la reflexión}

La observación densa y la identificación de patrones discursivos son las dos técnicas empleadas en la construcción de esta reflexión. La primera de ellas permitió la identificación de la contradicción ideológica que atraviesa la política local de vivienda, a través de la confrontación visual con una serie de realizaciones inmobiliarias de gran escala que están transformando el paisaje urbano y regional de ciudades y áreas metropolitanas de Colombia. En el apartado introductorio se da cuenta por medio de dos ilustraciones de esos fenómenos que apenas se encuentran en su estado inicial, pero que traerán a futuro muchas problemáticas ante las cuales la política pública territorial deberá construir nuevos lineamientos generales para el ordenamiento que les den respuesta.

La segunda técnica requirió la selección de documentos paradigmáticos de la planeación urbana-regional en Colombia, como se observa en el cuadro 1. De esos documentos se hizo una selección de apartados que muestran patrones discursivos asociados a las teorías de planeación urbana-regional imperantes para la época. Esos apartados se leen bajo la luz de esas teorías, lo cual permite su comprensión, especialmente en aquello relacionado con las visiones ideales de forma urbana y de orientación de las tendencias de crecimiento de las ciudades. 
Ciudad compacta vs. ciudad difusa

Ecos antiguos y recientes para las políticas de planeación territorial y espacial

\section{Cuadro 1}

Fuentes documentales para la identificación de patrones discursivos

\begin{tabular}{lll}
\hline $\begin{array}{l}\text { Etapa de planeación } \\
\text { para Colombia }\end{array}$ & $\begin{array}{l}\text { Especialistas } \\
\text { paradigmáticos }\end{array}$ & \multicolumn{1}{c}{$\begin{array}{c}\text { Documentos } \\
\text { referenciales }\end{array}$} \\
\hline $\begin{array}{l}\text { Planeación } \\
\text { Modernista }\end{array}$ & $\begin{array}{l}\text { Josep Lluis Sert, } \\
\text { Paul Lester Wiener } \\
\text { Le Corbusier }\end{array}$ & Plan Piloto de Le Corbusier para Bogotá (1950) \\
\hline $\begin{array}{l}\text { Planeación } \\
\text { Modernista }\end{array}$ & Paradigma \\
Comprehensivo & Pachlin Currie & $\begin{array}{l}\text { Operación Colombia (1960) } \\
\text { Ciudades dentro de la Ciudad (1974) } \\
\text { Ley Orgánica de Desarrollo Urbano (1978) }\end{array}$ \\
\hline $\begin{array}{l}\text { Planeación } \\
\text { Contemporánea } \\
\text { Paradigma de la } \\
\text { competitividad y } \\
\text { sostenibilidad }\end{array}$ & & \\
\hline
\end{tabular}

Fuente: elaboración propia

Finalmente, se exponen los principios contemporáneos que guían los debates de orientación de tendencias de crecimiento urbano. Por medio de un análisis comparativo básico se exponen los principios de desarrollo urbano a los cuales apela cada uno de ellos, sus ventajas y desventajas desde una perspectiva comparada. 
1. Un documental reciente llamado The Pruitt-Igoe Myth: an Urban History (2011) muestra de qué manera se dio ese proceso en la ciudad de St. Louis a mediados del siglo XX.

\section{La comisión de urbanistas y el corazón de la ciudad}

A finales de la primera mitad del siglo XX, una comisión integrada por los arquitectos Josep Lluis Sert, Paul Lester Wiener y Le Corbusier se encargó de asesorar la formulación en Colombia de los planes piloto y regulador de Tumaco (1947), Medellín (1948), Bogotá (1949) y Cali (1949); posteriormente, e inspirados en los lineamientos de la comisión, aparecerían otros planes como el Plan Piloto para la ciudad de Tunja (1958). En todos se planteaba la reconstrucción de los centros tradicionales de las ciudades, en un momento crítico de expansión urbana para el país (AdAms, 1969; Dureau \& Flórez, 1996), y que ello sirviera para cumplir una quinta función del urbanismo, la del "corazón de la ciudad" o "centro cívico".

Para la época en que la comisión llega al país y asesora la formulación de dichos planes, se daba un debate interno entre los miembros del CIAM sobre la necesidad de que en las políticas de planeación urbana y regional se incorporara dicha función. Esta debía ser capaz de responder a los nuevos retos derivados de los procesos de metropolización intensiva de muchos centros urbanos en el mundo, lo que estaba derivando en tendencias de crecimiento urbano atomizado. Al respecto, según datos ofrecidos por Donald L. FolEy (1972: vi), "hacia 1950 ya existían más de 90 áreas metropolitanas en el mundo con más de un millón de habitantes cada una”, en muchas de las cuales se evidenciaban tendencias de dispersión, que daban lugar a formas urbanas explayadas y aparentemente caóticas. En algunos centros urbanos norteamericanos, por ejemplo, se dio un fenómeno de migración inverso, con salida de población de los centros tradicionales hacia áreas suburbanas, lo cual aceleró su atomización ${ }^{1}$.

Los preámbulos de algunos de los planes locales que la comisión asesoró o inspiró en ese momento dejan entrever la preocupación que mostraban los consultores de que una forma urbana difusa se posicionara como la predominante en las ciudades que estaban bajo su encargo. Esto resaltaba, por ejemplo, LE CoRBusier de Bogotá a mediados del siglo XX en el Plan Regulador para Bogotá (el subrayado no es original): "La Ciudad de Bogotá (...) se había mantenido como una bella ciudad, construida sobre el trazado español y desarrollada de manera armoniosa alrededor de su centro, (...) en estos últimos años, el cambio que se ha dado en todas las ciudades del mundo ha destruido la armonía que existía en Bogotá. La ciudad se ha desarrollado, de lejos, sin orden ni razón y ha tomado 
una extensión anormal (Le CoRbusier, 1949) ${ }^{2}$. Y esto afirmaba otro consultor sobre la expansión de Tunja, capital del departamento de Boyacá: "Se anota un estado de dispersión que es preciso atacar ${ }^{3}$. Para ello la política territorial se orientará hacia la saturación del casco urbano (...) Al concentrar en esta forma la población se estará terminando de desarrollar todo aquello que racionalmente tiene un un principio de progreso" (PLAN PILOTO DE TUNJA, 1958).

Tales afirmaciones escondían la necesidad que tenían dichos consultores, en aquel momento, de defender la visión de un urbanismo moderno que hasta ese momento se había posicionado bajo el influjo ideológico de los CIAM, pero que ya mostraba signos de crisis y agotamiento. De acuerdo con VALDIVIA (2000: 25), el urbanismo de los CIAM no solo conduce y condiciona los resultados urbanísticos del Movimiento Moderno, sino que penetra además intensamente en la tradición anglosajona del planning y aparece como interlocutor imprescindible del organicismo y de los continuadores de la städtebau. Bajo ese influjo el urbanismo entendía la ciudad como una "forma compacta de asentamiento" (NEUman, 1991: 344), objeto moldeable con las herramientas del diseño físico (TAYLOR, 1998), que debe contar con un núcleo plenamente identificable, a partir del cual puede evolucionar, incluso descentralizarse, pero de manera ordenada.

Una forma urbana difusa contrariaba de raíz esos postulados básicos del urbanismo modernista y, sobre todo, cuestionaba la necesidad de un núcleo urbano o de varios de ellos. Vale la pena mencionar que desde los primeros CIAM se estableció que el urbanismo podía orientar procesos de expansión de la ciudad sobre el territorio, pero si se mantenían en ella núcleos urbanos o centralidades claramente identificables. Al respecto, DomHARDT (2012) explica que desde los primeros congresos de la CIAM llevados a cabo entre los años 1928-1930, "la idea de direccionar el problema de la rampante urbanización con descentralización gradual de las grandes ciudades y una planeada reorganización de sus centros culturales y sociales fue muy importante para el desarrollo inmobiliario urbano". Incluso la propuesta de "ciudad jardín" de Ebenezer Howard, que fue una de las vertientes que alimentó el urbanismo moderno, promovía una forma planeada de descentralización (FISHMAN, 1998), que se basaba en self-containedtowns, unidades de desarrollo urbano "limitadas tanto en términos de población como en grados de expansión geográfica, siendo concebidas como organismos urbanos económicamente independientes con su propia industria y agricultura” (DомнаRDT, 2012: 4).
2. Revisar: http://www. lecorbusierenbogota.com/ template.php?pg=includes/ elproyecto.

3. Resulta curioso pensar qué tan "dispersa" podía estar la ciudad de Tunja en la década de los 50, cuando actualmente no cuenta con más de 200.000 habitantes. 
El espacio regional circundante a lo urbano tampoco podía escapar a la lógica implacable del mantenimiento de la compacidad. Al respecto, las invenciones de la primera mitad del siglo XX, como el avión y la fotografía área (Boyer, 2003), ayudaron a que los urbanistas modernistas fortalecieran dicha pretensión ideológica. Al respecto, lo siguiente se afirma sobre el influjo que tuvieron estas invenciones en la mentalidad urbana-regional de LE CoRBUSIER: "La percepción del paisaje desde un avión le permitió a Le Corbusier desarrollar una nueva conciencia sobre la manera en que éste era configurado en sus atributos naturales... Esta herramienta le permitiría concebir sus estructuras geomorfológicas a través del espacio, representar la existencia de parcelas de tierra obsoletas, formas de la ciudad, y sus fronteras regionales y nacionales” (BOYER, 2003: 4-7).

La mirada desde arriba de lo urbano y regional permitió al urbanismo continental europeo representado por LE CORBUSIER fortalecer la idea de que el urbanismo tenía como una de sus finalidades orientar el crecimiento de las ciudades manteniendo formas urbanas compactas. En ese orden de ideas, Le CoRbusier asumió el paisaje circundante a la ciudad como el soporte o el "barro" de la arquitectura que precisamente permitía la construcción de su compacidad e univocidad (BOYER, 2003). El avance técnico del momento, en vez de hacerle ver la incertidumbre que la complejidad de los territorios le impregnan al desarrollo urbano, reforzó la defensa que hacía de la esencia organicista y mecanicista que el paradigma modernista le había impreso a la práctica del urbanismo. Su concepción de la geografía mantendría una visión simétrica y cartesiana del espacio (BOYER, 2003: 108) y fortalecería la inercia discursiva de la legitimidad de la planificación tradicional vertical, que debía ser siempre protegida de la amenaza que representaban las incipientes urbanizaciones tipo sprawl.

La lucha por mantener legítimo el ideal de la forma urbana compacta, sobre todo por la conservación del núcleo o, por lo menos, núcleos urbanos identificables, a juicio de esta reflexión no reflejaba sino el afán de mantener vigente el paradigma modernista del urbanismo, que cada vez más era relegado y controvertido interna y externamente. Efectivamente, Mumford destaca las luchas intestinas de carácter político y social que se estaban dando dentro del paradigma del urbanismo modernista durante la década de los 40 . El afán que mostraban muchos de sus representantes de recuperar la "simpatía social", de adecuarse a las demandas de partidos social-demócratas o de integrarse con otras asociaciones rivales de planificación o de arquitectura (Mumford, 2004: 164-167). En ese contexto de crisis se po- 
sicionó el liderazgo SERT, quien mientras residió en EE. UU. conoció a autores paradigmáticos de la mentalidad anti-sprawl, como Lewis Mumford y Sigfried Giedion. Defendió la vigencia del urbanismo modernista considerando que este debía "encarar el dificultoso problema del núcleo de la ciudad” (SERT; citado por Mumford, 2004: 203).

Fue precisamente idea de SERT la definición de la quinta función "el corazón de la ciudad”. La primera vez que apareció fue precisamente en una propuesta de rescatar la noción de "monumentalidad" en plena Segunda Guerra Mundial, hecha por el mismo SERT y SigfrIED Giedion. Noción que el urbanismo modernista había desconocido sistemáticamente por el afán precisamente de consolidar la ciudad moderna en oposición a la "ciudad tradicional", a la cual estaba asociada precisamente la idea del monumento. Al principio, SERT presionó por su cuenta en los CIAM para que se estableciera en un manifiesto la idea de que el urbanismo debía incorporar la quinta función con el fin de proteger la integridad del núcleo urbano. Lo hizo, al principio, publicando en el texto The Human scale in cityplanning (1944) la siguiente recomendación: "diseñar ciudades basadas en la unidad compacta de vecindario” (SERT, 1944; citado por Mumford, 2002: 151-152), y donde añadía que "el centro cívico y cultural constituye el elemento más importante” (SERT, 1944; citado por MumFoRD, 2002: 152). Aunque al comienzo la interpretación de centro cívico monumental que hizo LE CoRbusier de las ideas de SERT, tanto en el proyecto de Motor City en Brasil como en la propuesta de reconstrucción de St. Die (Mumford, 2002), no fue la más ortodoxa, en términos generales sirvió como una excusa para mantener vigente el paradigma del urbanismo moderno y la compacidad como atributo esencial de lo urbano.

La aparición de la quinta función en el CIAM VI solo se afianzaría posteriormente en el CIAM VII, en el cual precisamente SERT presentaría los planes reguladores para la ciudad colombiana de Tumaco y la ciudad peruana de Chimbote, incorporando en ellos la función de un centro cívico. Finalmente, dicha función sería promulgada como esencial a la práctica del urbanismo moderno en el CIAM VIII. Allí se daría uno de los últimos intentos de urbanistas modernistas de relegitimar su visión del urbanismo y de la compacidad como esencia de lo urbano. Las premisas de ese discurso curiosamente serían consolidadas por una nueva generación de planificadores que, si bien ya no responderían a los preceptos del urbanismo moderno, mantendrían la vigencia de ese ideal de ciudad compacta, así fuera a través de las nuevas razones ideológicas que les proveería, en parte, el nuevo paradigma sistémico de la planeación urbana y regional. 
El metabolismo nipón (1958-1975) enfrentaría el problema de la densidad con expansiones lineales futuristas y megaislas artificiales (tal como ofrece hoy el mercado inmobiliario de Dubai y Shangai), pero no para unas elites, sino para los obreros; el Archigram Inglés (196074) postularía grandes estructuras flexibles y extensibles, extrapolables hoy a las ciudades móviles en las periferias estadounidenses, entre otras. Si se observa con atención, ellas confinan en estructuras complejas los servicios urbanos para unas altas masas de población (lo que se podría asociar a compactación y autosuficiencia), pero ellas, aunque son ambiguas locacionalmente, expanden la ciudad con cierta independencia de los núcleos urbanos tradicionales, a diferencia de los planteamientos de LE CORBUSIER y de la comisión, expresados durante este apartado.

\section{Lauchlin Currie y ciudades dentro de la ciudad}

Así como la comisión de urbanistas llegó a Colombia en un momento crítico para el urbanismo modernista, el arribo de LAUCHLIN CURRIE significaría la llegada de unas ideas sobre la planeación basadas en el paradigma comprehensivo o sistémico, las cuales eran objeto de discusión en el mundo occidental desarrollado. CurRIE fue un economista canadiense, representante estrella del New Deal (TAYLOR, 1968) y teórico de fama internacional del keynessianismo (CoATs, 1983). En una primera etapa, CuRRIE sirvió a los gobiernos de algunos países en vía de desarrollo — como China y Colombia- para entender el papel del Estado como director del desarrollo económico y social.

CURRIE llega a Colombia, a finales de 1949, como líder de una misión del Banco Internacional de Reconstrucción y Fomento (Banco Mundial). Propuso al gobierno de ese entonces un Programa de Fomento para Colombia, que tenía como objetivo central "el aumento auto-generado del nivel de vida de áreas sub-desarrolladas" (CURRIE 1975: 102). A partir de 1960, y con la presentación de su obra Operación Colombia (1960), CuRRIE pasa a ser un especialista local que legitimó en Colombia la idea de que la planeación urbana debía responder a los siguientes postulados comprehensivos:

- La práctica de la planeación debe depender de los condicionantes económicos y no solo de los estéticos, y al respecto afirmaba: "la planeación ha sido considerado demasiado a menudo un asunto estético, de asegurar suficiente luz y aire, que no ha tenido suficientemente en cuenta el poder de las fuerzas económicas” (CURRIE, 1975: 39). 
- La práctica de la planeación debe integrarse a un objetivo fundamental de desarrollo. Dentro de la lógica procedimental no podía haber espacio para la improvisación. Para CURRIE una práctica de PU no estaba nunca desligada de una necesidad concreta de la sociedad, como se pone de ejemplo a continuación: "si fomentar el crecimiento económico implica un incremento en la producción de bienes y servicios en precios constantes, y eso, puede ser únicamente logrado más rápidamente en las ciudades, entonces lo más lógico es pensar que la orientación de la urbanización y el desarrollo se deben integrar" (CURRIE, 1975: 38).

- La planeación requiere una estructura administrativa principal que gestione el desarrollo de su práctica en todos los niveles. CuRrie sugirió en Colombia la creación de una única entidad de orden nacional que permitiera "atacar", al mismo tiempo, problemáticas de desarrollo en el ámbito urbano, social y económico reforzando el supuesto de que "probablemente nadie discutiría con la idea de que la planeación urbana deba ser parte integral de la planeación nacional, entre otras cosas porque esto ya es una realidad" (CURRIE, 1975: 37).

La actitud proclive de CuRRIE a la intervención del Estado en todas las dimensiones sociales y económicas, dado su enfoque neo-keynessiano, generó cierto recelo en la clase política norteamericana, que lo alejó de los centros de decisión local, por sospechas de ser un espía del comunismo chino. Terminó viviendo finalmente en Colombia desde comienzos de la década de los 70, tiempo durante el cual asesoró la formulación de planes nacionales y locales de desarrollo. Aprovechó esta situación para insistir en su idea de desarrollo urbano basado en el policentrismo, como opuesto diametralmente a cualquier intento de defensa del sprawl. Así entonces, CuRRIE emuló la pretensión de compacidad urbana del urbanismo modernista, claro está, teniendo motivaciones de índole económica principalmente. Y al igual que los representantes del urbanismo modernista, CuRRIE se oponía a lo que estaba pasando en el contexto norteamericano, donde sectores políticos y económicos se habían comprometido con la promoción de las formas urbanas difusas. La voz de él junto con algunos otros especialistas en temas de ciudad (como Jane Jacobs y el mismo Lewis Mumford), que insistían en la necesidad de mantener la vida urbana tradicional basada en la conservación de un núcleo cívico, no solo por razones culturales, sino también económicas, fue minimizada en EE. UU. por unas tendencias explosivas de crecimiento urbano orientadas a la consolidación de formas urbanas difusas, como la de Los Ángeles en el Estado de California.

Hay que recordar que, para finales de los 60, el diagnóstico que CuRRIE hizo de la situación urbana en Colombia mostraba que el desarrollo de una política de orientación de la urbani- 
zación para el país debía ser una alternativa a los tres paradigmas que existían, a saber: $a$ ) el modelo anglosajón, que se basaba en la creación de ciudades nuevas; $b$ ) el modelo norteamericano, que se basaba en la construcción de suburbios y c) el modelo asiático, que combinaba la urbanización expansiva con altas densidades habitacionales. CuRRIE sugirió entonces adoptar un modelo de desarrollo urbano denominado cities-within-cities (new towns in town), que respondía a su visión del desarrollo urbano ideal basado en los preceptos de la planeación comprehensiva y de la compacidad. Su estructura básica era "la provisión de vivienda, empleos y servicios concentrados en una única localidad" (GAKENHEIMER, 1976: 51). El principio urbanístico básico para la implementación del modelo era el de la autosuficiencia: "la misma gente que vive en una localidad además trabaja allí, creando así una atmósfera comunitaria y generando ahorros en los costos de viaje” (GAKENHEIMER, 1976: 51).

Así entonces, por un lado, el modelo cities-within-cities se constituía en una alternativa que servía a varios propósitos sistémicos del desarrollo: estimular el crecimiento económico, superar la situación de desempleo estructural, bajos ingresos y de informalidad habitacional en el espacio urbano. Por otra parte, el modelo se basaba en la idea de generar núcleos urbanos identificables, tal cual a la manera de algunas vertientes del urbanismo modernista. Este modelo de orientación del crecimiento urbano fue originalmente formulado y administrado por el US Department of Housing and Urban Development en la década de los 60 en EE. UU. (GAKENHEIMER, 1976: 51), pero en dicho país esta propuesta fue sistemáticamente desconocida por muchos de los estados federales.

Solo en Colombia se pudo realmente incorporar en documentos oficiales de política urbana a nivel nacional y local, como en el documento Ciudades dentro de la Ciudad del Departamento Nacional de Planeación en 1974 (CurRiE, 1975) y en el Plan de Desarrollo de las Cuatro Estrategias, de 1971, del gobierno de Misael Pastrana Borrero (GARRIDo 2004). Es posible, además, rastrear algunos principios de este modelo en la Ley Orgánica de Desarrollo Urbano, Ley 61 de 1978, que obligaba a los municipios de más de 20.000 habitantes a formular Planes Integrados de Desarrollo, con el objetivo de "lograr condiciones óptimas para el desarrollo de las ciudades y de sus áreas de influencia en los aspectos físico, económico, social y administrativo [...] con base en las técnicas modernas de PU y de coordinación urbano-regional”. En el plan que la Alcaldía de Bogotá formuló para dar cumplimiento a la anterior ley, Acuerdo 7 de 1979, se obligaba, por ejemplo (subrayado no original), a "estimular la utilización y densificación de las áreas localizadas al Sur y al Occidente de la Ciudad [...] Promover 
el incremento de la densidad en las áreas desarrolladas, así como la densificación de aquellas por desarrollar, a fin de obtener por esa manera un uso más intenso del suelo urbano, evitar la expansión horizontal de la Ciudad y la generación de nuevas centralidades”.

Las recomendaciones para política urbana de CuRRIE conservarían el mismo rechazo del sprawl y el mantenimiento de formas urbanas compactas para las ciudades del país. Al respecto, él afirmaba (subrayado no original): "the task of the urban planner who would fit urban design into this framework is to accept a rapid growth in urbanisation but seek, at the same time, to avoid or lessen the evils or disadventages associated with rapid growth" (CURRIE, 1975: 46). Los componentes urbanos de la planeación comprehensiva o sistémica que se posicionaría en Colombia a partir de la década de los 60 reflejarían posteriormente el supuesto dominante de que la orientación de los fenómenos asociados al crecimiento expansivo de las ciudades debe llevar al mantenimiento y consolidación de formas urbanas compactas.

\section{Discusión contemporánea}

Actualmente persisten muchos supuestos alrededor de la compacidad y difusión urbanas que deben ser revalorados (figura 3). Por ejemplo, la Agencia Europea de Medio Ambiente (EEA, 2006) continúa describiendo el sprawl como un patrón de crecimiento físico tentacular, expansivo, de baja densidad y poco regulado, el cual se asocia con ciudades atomizadas vinculadas con procesos de conurbación y suburbanización, al amparo del desarrollo y extensión superficial de la ciudad industrial sobre su periferia rural inmediata, favorecida por el incremento de la capacidad de movilidad residencial y de los medios de transporte (HerverT, 1973; Clout, 1974). Pero también a procesos de contraurbanización, movimientos centrífugos de personas y actividades económicas desde las grandes ciudades hacia los pequeños asentamientos urbanos y rurales, particularmente en los países más desarrollados (BeRRY, 1976; Fielding, 1982). Condiciones emergentes en las fases de desregulación económica propias del neoliberalismo (FERRÁs, 2000). En tanto, a la ciudad compacta se la sigue asociando con el crecimiento espacial polarizado propio de la era industrial y basado en la idea de proximidad de los componentes que conforman la ciudad, es decir, la reunión en un espacio más o menos limitado de los usos y las funciones urbanas (RUEDA, 2009). 
Servicios Urbanos

\section{Ciudad difusa, especializada y de alta movilidad}

Residencial de alta

y moderada

densidad

Residencial

suburbano de

baja movilidad
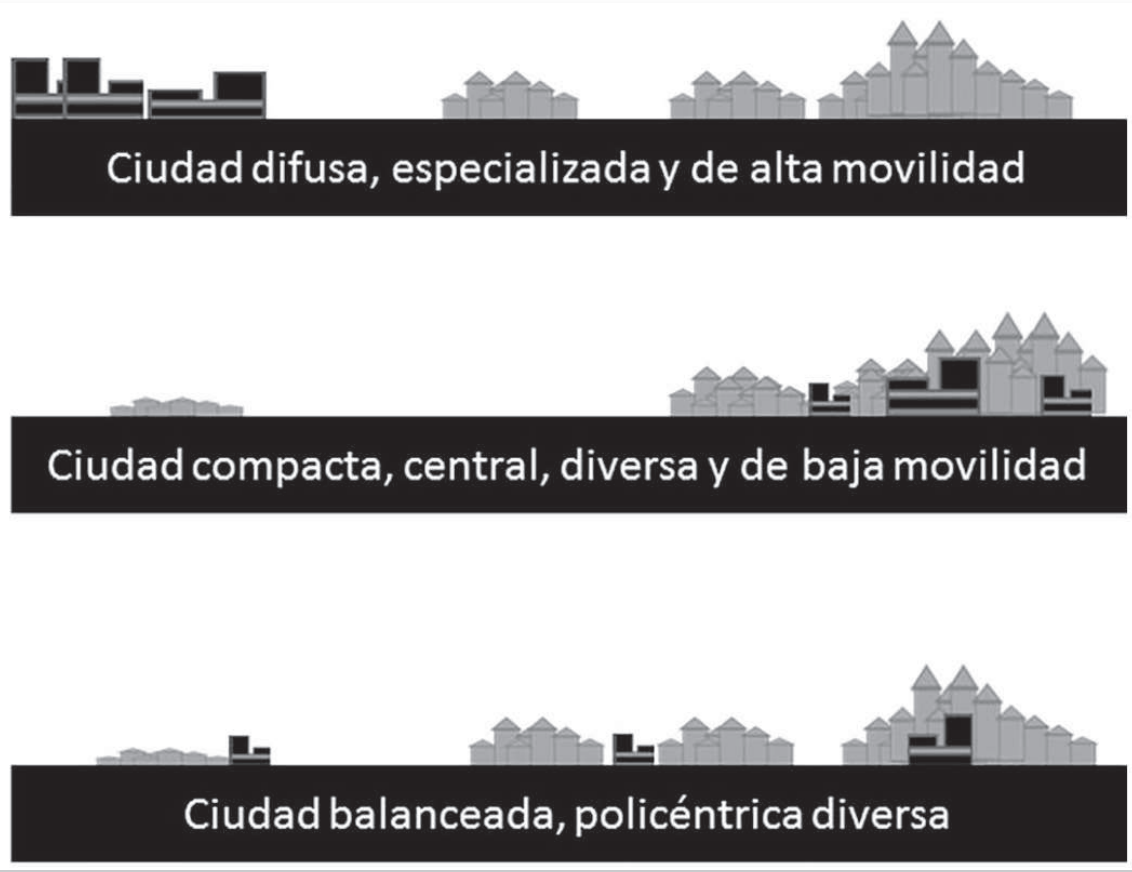

Figura 3. Patrones de ordenamiento de la ciudad compacta y difusa

Fuente: elaboración propia
Sin embargo, esos atributos tradicionalmente asignados a esas dos formas urbanas no son tan exactos como pareciera. Hoy en día, por ejemplo, se pueden dar formas urbanas compactas que son consecuencia de una deficiente planificación de las tendencias de crecimiento expansivas. También se pueden dar formas urbanas difusas con altas densidades habitacionales, y constituirse ello en el peor de los mundos deseables. Tampoco es cierto que la compacidad sea, de facto, más sostenible ambientalmente que el sprawl. Se suele considerar que las recetas de contención son las más transferibles a países en vías de desarrollo 
con crecimiento expansivo, pero algunos autores señalan que "los costos y los beneficios de la contención de las ciudades son inciertos y su contribución potencial es cuestionable” (ÁNGEL, 2014: 11), ya que, por ejemplo, las evidencias señalan que las emisiones están asociadas más causalmente al estilo de vida que a las densidades, por los efectos sobre el hacinamiento, la iluminación, la polución, la congestión, la sobrecarga del suelo y de infraestructuras y por los impactos de la escasez de suelo urbanizable sobre el costo de las viviendas.

Arellano (2011), al sostener que la "ciudad jardín" es el culmen del urbanismo difuso, pone en cuestión la baja planificación que usualmente se asocia al sprawl; es decir que se trata también de un patrón de ordenación urbanística que media la conquista de unos fines. De hecho, la misma Arellano, apoyada en el texto de Galster et ál. (2001), propone la hipótesis de que el sprawl, que representó a principios del siglo XX una forma de urbanismo vernácula (cuya forma más acabada representó la Garden City de Howard a diferencia de lo expresado en páginas anteriores), se ha convertido, especialmente a partir de la década de los 70, en "la tendencia generalizada a escala global", que condiciona políticas de planeación urbanas y regionales.

El sprawl no necesariamente es sinónimo de desregularización de las tendencias de crecimiento, así como tampoco compacidad lo es de orden y de planificación exitosa. A propósito de algunos procesos de metropolización y regionalización basada en redes, apuntan a este tipo de configuración espacial en respuesta a las dinámicas económicas contemporáneas y pretenden la vinculación no jerárquica de los asentamientos incluidos, donde tendencias de dispersión bien encaminadas pueden ayudar a consolidarlos. Borx (2005: 225), soportado en RAFFESTIN (1981), afirma que "la visión areal es el instrumento del estado territorial, del control burocrático y la planificación jerárquica, frente a la red, que es la respuesta de los sistemas urbanos a las necesidades de dinamismo y flexibilidad en la respuesta económica y en la implementación de políticas, en un contexto de cambio y globalización”. La red se asocia a algunos de los conceptos que dominan el lenguaje y la práctica del ordenamiento territorial y de la geografía económica contemporánea, tales como gobernanza, economías de aglomeración y complementariedad locacional.

Otro aspecto que cabe mencionar es que así como se indican los efectos negativos de la dispersión, también los modelos compactos los muestran. El cuadro 2 explicita algunas de las dificultades, impactos o retos que entraña cada forma urbana. 
Cuadro 2

\begin{tabular}{|c|c|c|}
\hline $\begin{array}{l}\text { Condición } \\
\text { de comparación }\end{array}$ & $\begin{array}{l}\text { Ciudad difusa } \\
\text { especializada y dispersa }\end{array}$ & $\begin{array}{l}\text { Ciudad compacta } \\
\text { diversa y densa }\end{array}$ \\
\hline $\begin{array}{l}\text { Complejidad del } \\
\text { sistema urbano }\end{array}$ & $\begin{array}{l}\text { Consume materia y energía a expensas de la } \\
\text { simplificación de las interacciones. }\end{array}$ & $\begin{array}{l}\text { Aumenta la complejidad de las relacio- } \\
\text { nes en el interior del sistema de ciudad. }\end{array}$ \\
\hline Crecimiento & $\begin{array}{l}\text { Horizontal. Plantea la inevitabilidad del creci- } \\
\text { miento demográfico y como consecuencia de la } \\
\text { expansión. }\end{array}$ & $\begin{array}{l}\text { Vertical y llenar los intersticios urbanos. } \\
\text { Las ciudades ya han alcanzado un tamaño } \\
\text { amenazante. }\end{array}$ \\
\hline Densidad & $\begin{array}{l}\text { Baja, pero reconoce la necesidad de densidades } \\
\text { que hagan viable el transporte público. }\end{array}$ & $\begin{array}{l}\text { Alta, ya que entre mayor densidad, menor } \\
\text { espacio para acomodar a su población. } \\
\text { Pero ciudades con elevadas densidades su- } \\
\text { ponen hacinamiento, congestión y sobre- } \\
\text { carga del suelo e infraestructuras. }\end{array}$ \\
\hline $\begin{array}{l}\text { Origen } \\
\text { morfológico }\end{array}$ & $\begin{array}{l}\text { Se basa en el desarrollo de las comunicacio- } \\
\text { nes y tecnologías que permiten economías } \\
\text { deslocalizadas y un estilo de vida afín al sue- } \\
\text { ño americano. }\end{array}$ & $\begin{array}{l}\text { Afín con estilos de vida de la Europa me- } \\
\text { diterránea. Se basa en la proximidad para } \\
\text { ahorrar materia y energía, reducir las dis- } \\
\text { tancias a los servicios urbanos, pero impli- } \\
\text { ca una provisión más intrincada. }\end{array}$ \\
\hline Jurisdicción & $\begin{array}{l}\text { Los sistemas de asentamientos son desjerarqui- } \\
\text { zados, sobrepone jurisdicciones sin definición } \\
\text { clara de sus fronteras e implica nuevos instru- } \\
\text { mentos de gestión de carácter regional. }\end{array}$ & $\begin{array}{l}\text { La planificación, administración y gestión } \\
\text { son centralizadas, delimitadas jurisdiccio- } \\
\text { nalmente y jerárquicas, vinculadas asimé- } \\
\text { tricamente con asentamientos o jurisdic- } \\
\text { ciones adyacentes. }\end{array}$ \\
\hline Centralización & $\begin{array}{l}\text { Especialización funcional. Tiende a homogenei- } \\
\text { zar el territorio a través de unidades monofun- } \\
\text { cionales compactas para maximizar el acceso a } \\
\text { sus centros de negocios }\end{array}$ & $\begin{array}{l}\text { Diversidad y heterogeneidad socioeconó- } \\
\text { mica, tipológica y funcional. Exacerba el } \\
\text { conflicto por el suelo, la invasión de lo pú- } \\
\text { blico y propicia la incompatibilidad. }\end{array}$ \\
\hline
\end{tabular}


Ciudad compacta vs. ciudad difusa

Ecos antiguos y recientes para las políticas de planeación territorial y espacial

Fuente: elaboración propia

\begin{tabular}{|c|c|c|}
\hline $\begin{array}{l}\text { Condición } \\
\text { de comparación }\end{array}$ & $\begin{array}{l}\text { Ciudad difusa } \\
\text { especializada y dispersa }\end{array}$ & $\begin{array}{l}\text { Ciudad compacta } \\
\text { diversa y densa }\end{array}$ \\
\hline $\begin{array}{l}\text { Disponibilidad } \\
\text { de suelo }\end{array}$ & $\begin{array}{l}\text { Considera el suelo un recuso con pocas limi- } \\
\text { taciones, ya que se adquiere suelo rural o de } \\
\text { pequeños asentamientos a bajo costo. }\end{array}$ & $\begin{array}{l}\text { Pocas disponibilidades y encarecimiento } \\
\text { de suelo y las infraestructuras, lo que } \\
\text { dificulta el acceso de los más pobres a una } \\
\text { vivienda digna. }\end{array}$ \\
\hline $\begin{array}{l}\text { Movilidad } \\
\text { funcional }\end{array}$ & $\begin{array}{l}\text { Aumenta haciendo esencial el transporte } \\
\text { privado motorizado, vías más grandes, vehí- } \\
\text { culos más rápidos y elevadas inversiones para } \\
\text { comunidades reducidas. }\end{array}$ & $\begin{array}{l}\text { Disminuye. Hace esenciales las vías mul- } \\
\text { tipropósito, la utilización del subsuelo y } \\
\text { la descentralización de servicios y centros } \\
\text { de empleo; pero fomenta la congestión } \\
\text { vehicular. }\end{array}$ \\
\hline Impacto social & $\begin{array}{l}\text { Polariza la separación entre ricos y pobres. } \\
\text { ¿No son las familias acomodadas las que pue- } \\
\text { den vivir en una casa unifamiliar en el campo } \\
\text { y continuar vinculadas funcionalmente con la } \\
\text { ciudad? (FERRÁS, 2000) }\end{array}$ & $\begin{array}{l}\text { Facilita el acceso de servicios básicos, pero } \\
\text { segrega zonas por el costo de su inmedia- } \\
\text { tez. Además entraña dificultades para su } \\
\text { abastecimiento. }\end{array}$ \\
\hline Interacción social & $\begin{array}{l}\text { Facilita la comunicación interurbana, pero } \\
\text { reduce la comunicación, la regulación y el } \\
\text { intercambio, con lo que pierde calidad el es- } \\
\text { pacio público, que ganan los sitios privados. }\end{array}$ & $\begin{array}{l}\text { Facilita la interacción social intraurbana } \\
\text { en el espacio público, pero le acompaña } \\
\text { la segregación espacial por la calidad } \\
\text { espacial. }\end{array}$ \\
\hline $\begin{array}{l}\text { Impacto } \\
\text { ambiental }\end{array}$ & $\begin{array}{l}\text { Despilfarro energético y de recursos para } \\
\text { dotar a una población desconcentrada. Mayor } \\
\text { consumo de suelo y probabilidad de ocupa- } \\
\text { ción más allá de la capacidad de carga. }\end{array}$ & $\begin{array}{l}\text { Alta concentración de servicios y de resi- } \\
\text { duos e intervención de ecosistemas cada } \\
\text { vez más lejanos para proporcionar los } \\
\text { crecientes servicios urbanos. }\end{array}$ \\
\hline $\begin{array}{l}\text { Autoorganización } \\
\text { física }\end{array}$ & Se ajusta a tendencias globales de mercado. & $\begin{array}{l}\text { Implica necesariamente un urbanismo } \\
\text { intervencionista sobre la propiedad y la } \\
\text { renta inmobiliaria. }\end{array}$ \\
\hline
\end{tabular}


En el caso del crecimiento urbano expansivo de mediados de siglo XX, en un contexto de sustitución de importaciones y promoción del consumo local, la orientación a la forma urbana compacta podía resultar más adecuada. Sin embargo, el crecimiento urbano expansivo actual está muy vinculado con las dinámicas económicas globalizantes de índole contemporánea, y podrían eventualmente ser orientadas de manera más exitosa a la consolidación de formas urbanas difusas.

Es posible que el quid del asunto no sea tanto defender compacidad por encima del sprawl, o la posición contraria, sino encontrar un punto de equilibrio (masa crítica) que, según SALvador Rueda (2009), haga viable la provisión de transportes, equipamientos y servicios por un grado adecuado de proximidad entre usos y funciones urbanas y de equilibrio del tejido urbano. Al respecto, propone un indicador que denomina "compacidad corregida", que relaciona el volumen construido de una determinada superficie urbana y el espacio de interacción social (espacio libre y público con anchuras superiores a cinco metros), pretendiendo un equilibrio entre espacios ligados a la funcionalidad y la organización urbana y espacios relacionados con la convivencia y el contacto con la naturaleza. RuEDA estima que una compacidad corregida de entre diez y cincuenta metros (sobre la malla de referencia) garantiza, al menos, un espacio de estancia de veinte metros cuadrados por persona.

Esto lleva a reflexionar sobre cuál es ese punto de equilibrio que permite las sinergias necesarias para el asentamiento. Una respuesta proporcionada por el mismo autor sería relacionar las rentabilidades que proporciona cierta complejidad de actividades. En esa medida, se trataría de las condiciones de densidad y diversidad para generar una renta que amortice las inversiones públicas en infraestructura y servicios. En la práctica, el número de personas, instituciones y actividades que justifique las inversiones; pero dadas las condiciones únicas de cada ámbito, se dificulta cualquier estandarización. No obstante, esta definición impide la lectura de las periferias urbanas como una masa crítica a no ser que sean incorporadas en un plan. Una propuesta de nueva planta o de mejoramiento barrial con un número de contribuyentes suficiente y con capacidad de pago para cubrir los costos de articulación urbana y dotación de servicios. Da paso así a una nueva segregación, al privilegiar nuevas centralidades urbanas en detrimento de las áreas populares de las periferias.

Otra opción complementaria es apostarle a una nueva escala de gestión: la territorial o regional, donde la incorporación de un nuevo asentamiento, adyacente o no, requiere que tenga o pueda obtener esa masa crítica con la capacidad de sufragar su anexión, compartiendo 
algunas inversiones con los asentamientos que entran a beneficiarse de esa articulación. De alguna manera lo que se deriva de esta afirmación es que cada uno de esos asentamientos configura núcleos, aunque no de la manera tradicional, y que es la articulación de estos núcleos lo que viabiliza la región. Los procesos de metropolización y de regionalización recientes liderados por Bogotá así lo muestran.

Los términos ciudad región o ciudad global expresan que la ciudad ya no es vista separada del campo y circunscrita a sus bordes, sino que se configura con nuevas escalas como un soporte de la estrategia de competitividad. EscoBAR (2012) compara las iniciativas presentadas para el caso de Bogotá en este siglo, y concluye que todas ellas proponen integrar centralidades y funciones con la estructura ecológica principal en un modelo desconcentrado, constituido por una red de ciudades de distinta jerarquía y función, partiendo del reconocimiento de la proximidad espacial, la complementariedad y las relaciones de interdependencia preexistentes. La última de estas iniciativas define una estructura conformada por tres grandes centralidades (Aerópolis, Centralidad de articulación de la Región Capital y Centralidad de articulación de la Subregión Sabana), nodos menores de integración en el interior de Bogotá y los ejes tecnológicos de innovación y desarrollo industrial, pero las centralidades priorizadas continúan estando en inmediaciones de la capital, y no deja claro la forma como los municipios periféricos entrarán a participar de forma activa en este modelo. Esto muestra una tendencia global que requiere nociones de gestión nuevas para operar horizontalmente en una ciudad que se sobrepone a las jurisdicciones territoriales tradicionales.

Entonces, no se trata ciegamente de llenar los vacíos e intersticios urbanos, de apostar por una renovación urbana en altura y eliminar las posibilidades de dispersión. Se trata de garantizar esa armonía por el equilibrio entre la vialidad y la habitabilidad, la quietud del campo con el movimiento citadino, lo construido y lo verde, que no es más al decir de RUEDA (2009) que "el equilibrio entre funcionamiento urbano y descompresión urbana bajo una visión de conjunto de la ciudad”. De esa forma, el problema claramente no consiste en insistir en la necesidad de pretender ciudades compactas o difusas; sino en el método de cómo se concibe dicha compacidad o difusión, en los supuestos teóricos que soportan esas pretensiones y, sobre todo, en el pleno conocimiento de las nuevas geografías económicas que refuerzan sus tendencias de crecimiento. Es posible que los urbanistas o planificadores urbanos y regionales todavía pretendan luchar contra esas tendencias, y sugieran políticas de orientación de ellas, apelando más al deseo de cumplir ideales supuestos que a los condicionamientos materiales. 


\section{Bibliografía}

ADAMS, Dale (1969). "Rural migration and agricultural development in Colombia”. En: Economic Development and cultural change, 17(4), 527-539.

ARELLANO, Blanca (2010). "El urbansprawl: un modelo de urbanización insostenible". Tesis doctoral. Programa de posgrado en Gestión y Valoración Urbana y Arquitectónica, Universidad Politécnica de Cataluña, España.

AUDIRAC, Ivonne; SHERMYEN, Anne; SMITH, Marc (1990). "Ideal urban form and visions of the good life: Florida's growth management dilemma”. En: Journal of the American Planning Association, 56 (4), 470-470.

BERRY, Brian Joe Lobley (1976) Urbanization and Counterurbanization. ARNOLD, Nueva York.

BOIX, Rafael (2006). "Redes de ciudades, economías externas y crecimiento”. En: La nueva cultura del territorio. Diputacio de Barcelona, Barcelona, 251-264.

BOYER, Christine (2003). "Aviation and the Aerial View: Le Corbusier's Spatial Transformations in the 1930s and 1940s". En: Diacritics, 33 (3-4), 93-116.

CLOUT, Hugh (1974). "The Growth of second-home ownership: an example of seasonal suburbanization”. En: Tijdschrift Voor Economische En Sociale Geografie, 63, 393-401.

CURRIE, Lauchlin (1975). "The interrelations of urban and national economic planning”. En: Urban Studies, 12, 37-46.

COATS, Alfred William (1983). "Reseña del libro: the role of economic advisers in developing countries de Lauchlin Currie”. En: The journal of Economic History, 43 (3), 770.

DEPARTAMENTO NACIONAL DE PLANEACIÓN (2005) "Visión Colombia II Centenario: 2019. Documento de política del Departamento Nacional de Planeación”. DNP, Bogotá.

DOMHARDT, Konstanze (2012). "The garden city idea in the CIAM discourse on urbanism: a path to comprehensive planning”. En: Planning Perspectives, 27 (2), 173-197.

DUREAU, Françoise; FLOREZ, Carmen (1996). "Dinámicas demográficas colombianas: de lo nacional a lo local”. En: Documento CEDE, 96 (01).

ESCOBAR, Nathalie (2012). "La noción de región en el proyecto de integración Bogotá-Cundinamarca. Una mirada comparada”. Trabajo de grado. Programa de Especialización en 
Urbanismo y Planeación Territorial, Fundación Universidad de América, Bogotá, Colombia. EUROPEAN ENVIRONMENT AGENCY (2006) "Urban sprawl in Europe. Theignored challenge. Documento de política de la European Commission/Joint Research Centre”. European Environment Agency, Copenhagen.

FERRÁS, Carlos (2000). “Ciudad dispersa, aldea virtual y revolución tecnológica. Reflexión acerca de sus relaciones y significado social”. En: Scripta Nova, 69(68). Disponible en: http:// www.ub.edu/geocrit/sn-69-68.htm (Consultado 21-04-2017).

FIELDING, James Allen (1982). “Counter urbanization in Western Europe”. En: Progress in Planning, 17 (1), 1-52.

FISHMAN, Robert (1998). "Howard and the garden”. En: Journal of the American Planning Association, 64 (2), 127-128.

FOLEY, Donald (1972) Governing the London region. University Of California Press, Los Angeles.

GARRIDO, José (2004) Lauchin Bernard Currie. Disponible en: http://www.banrepcultural. org/blaavirtual/biografias/currlauc.htm (Consultado 12-09-10).

GAKENHEIMER, Ralph (1976). "New towns in-town for developing countries: acomment". En: Urban Studies, (13), 51-54.

GALSTER, George; HANSON, Royce; RATCLIFFE, Michael; WOLMAN, Harold; COLEMAN, Stephen; FREIHAGE, Jason (2001). "Wrestling sprawl to the ground: defining and measuring an elusive concept”. En: Housing Policy Debate, 12 (4), 681-717.

HERVERT, David (1973). "The residential mobility process some empirical observations". En: Area, 5 (1), 44-48.

MUMFORD, Eric (2002) The Ciam discourse on urbanism, 1928-1960. MIT PRESS, Massachusetts.

NEUMAN, Michael (1991). Growth management reconsidered: Utopia, dystopia, diaspora. En: Journal of the American Planning Association, 57 (3), 344-344.

RUEDA, Salvador (2002) El Impacto de los Sistemas Urbanos. Disponible en: http://www. itescam.edu.mx/principal/sylabus/fpdb/recursos/r76034.PDF (Consultado 25-01-16). (2009). "El urbanismo ecológico: un nuevo urbanismo para abordar los retos de la sociedad actual”. En: Ingeniería para un mundo sostenible, 41, 49-83.

SALDÍAS, Carmenza (2009). "Las ciudades y regiones, la realidad territorial del desarrollo”. En: Revista de Ingeniería, 29, 82-95. 
TAYLOR, Milton (1968) "Reseña del libro: Acelerating development de Lauchlin Currie". En: The Journal of Political Economy, 76 (3), 500-502.

TAYLOR, Nigel (1988) Urban planning theory since 1945. Sage Publications, London.

VALDIVIA, Luque (2000). Constructores de la ciudad moderna. CIE Inversiones Editoriales, Madrid.

YU-HSIN TSAI (2005). “Quantifying urban form: Compactness versus 'sprawl””. En: Urban Studies, 42 (1), 141-161. 